Supplement of The Cryosphere, 11, 2555-2569, 2017

https://doi.org/10.5194/tc-11-2555-2017-supplement

(C) Author(s) 2017. This work is distributed under

the Creative Commons Attribution 3.0 License.

(c) (1)

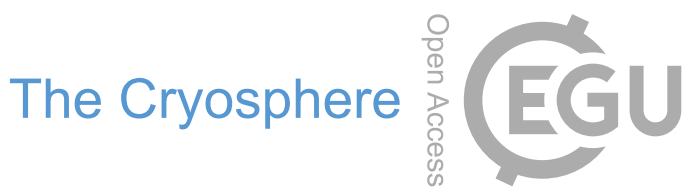

Supplement of

\title{
Blowing snow sublimation and transport over Antarctica from 11 years of CALIPSO observations
}

\section{Stephen P. Palm et al.}

Correspondence to: Stephen P. Palm (stephen.p.palm@nasa.gov)

The copyright of individual parts of the supplement might differ from the CC BY 3.0 License. 
Supplemental Figures to Paper TC 2017-45

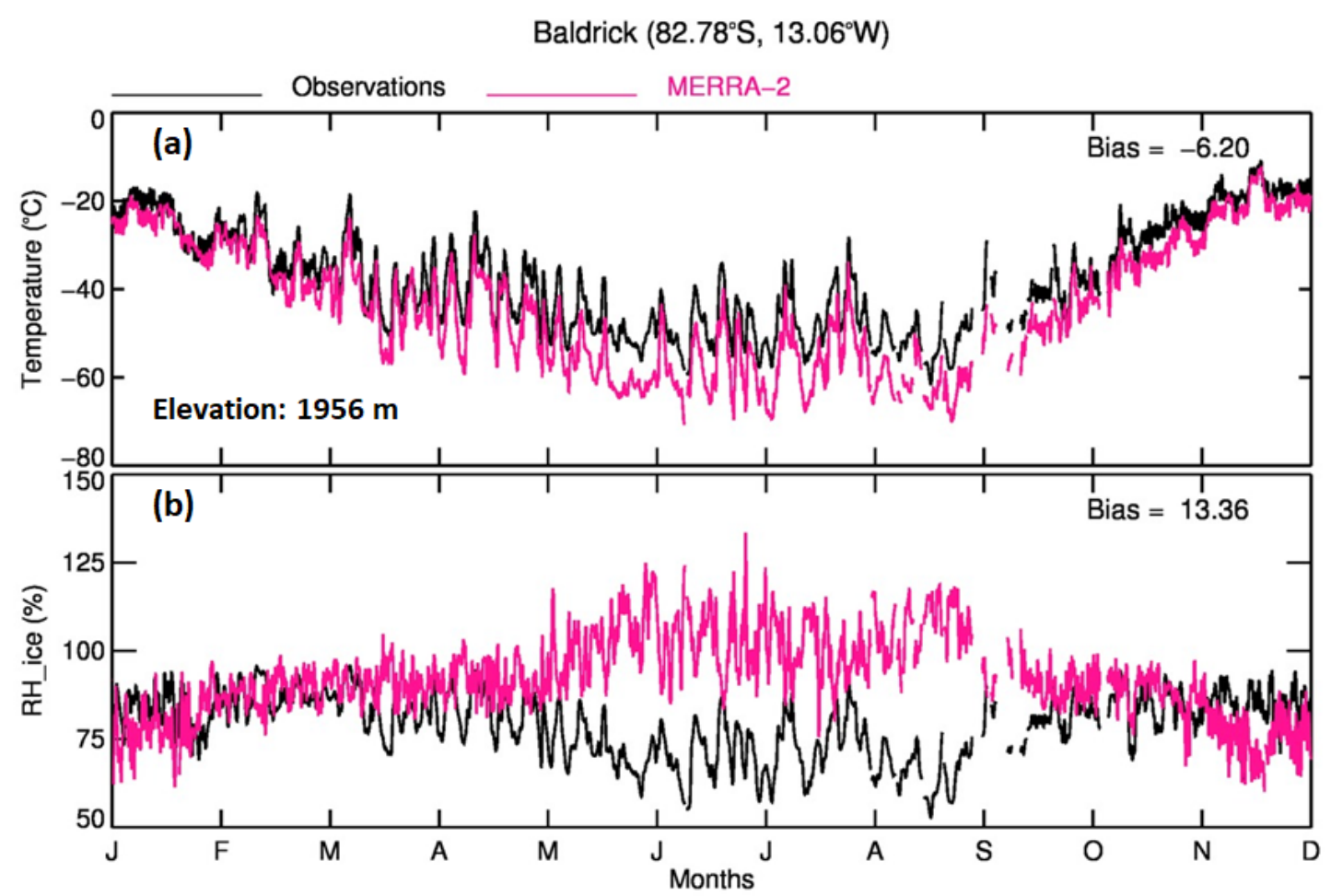

Figure S1. Automatic Weather Station (AWS) Baldrick (black) $2 \mathrm{~m}$ temperature (a) and relative humidity with respect to ice (b) plotted with the corresponding 2 m MERRA-2 data (pink) closest in space and time to the AWS observation for 2016. 


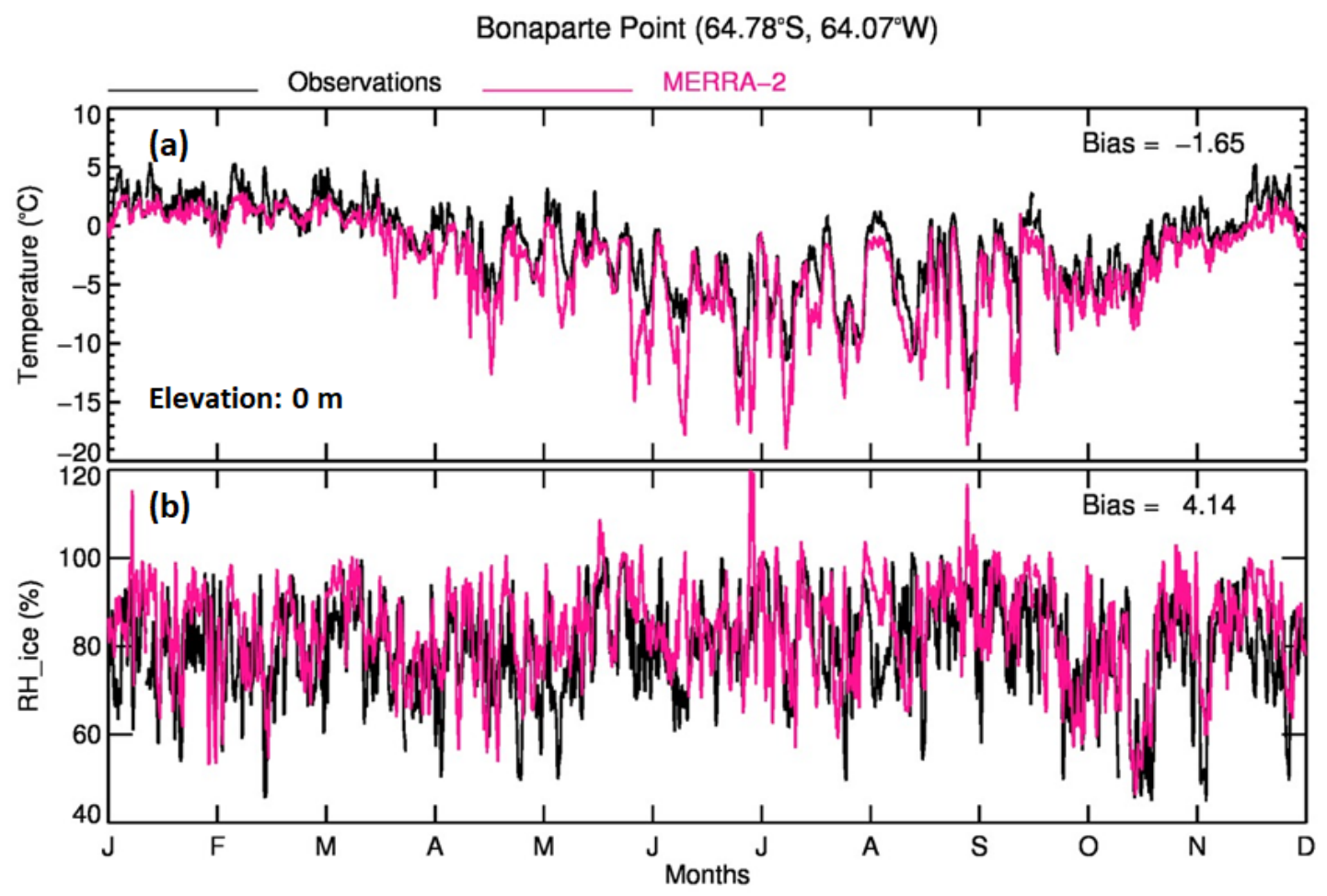

Figure S2. Same as Figure S1, except for AWS Bonaparte Point and for 2009. 


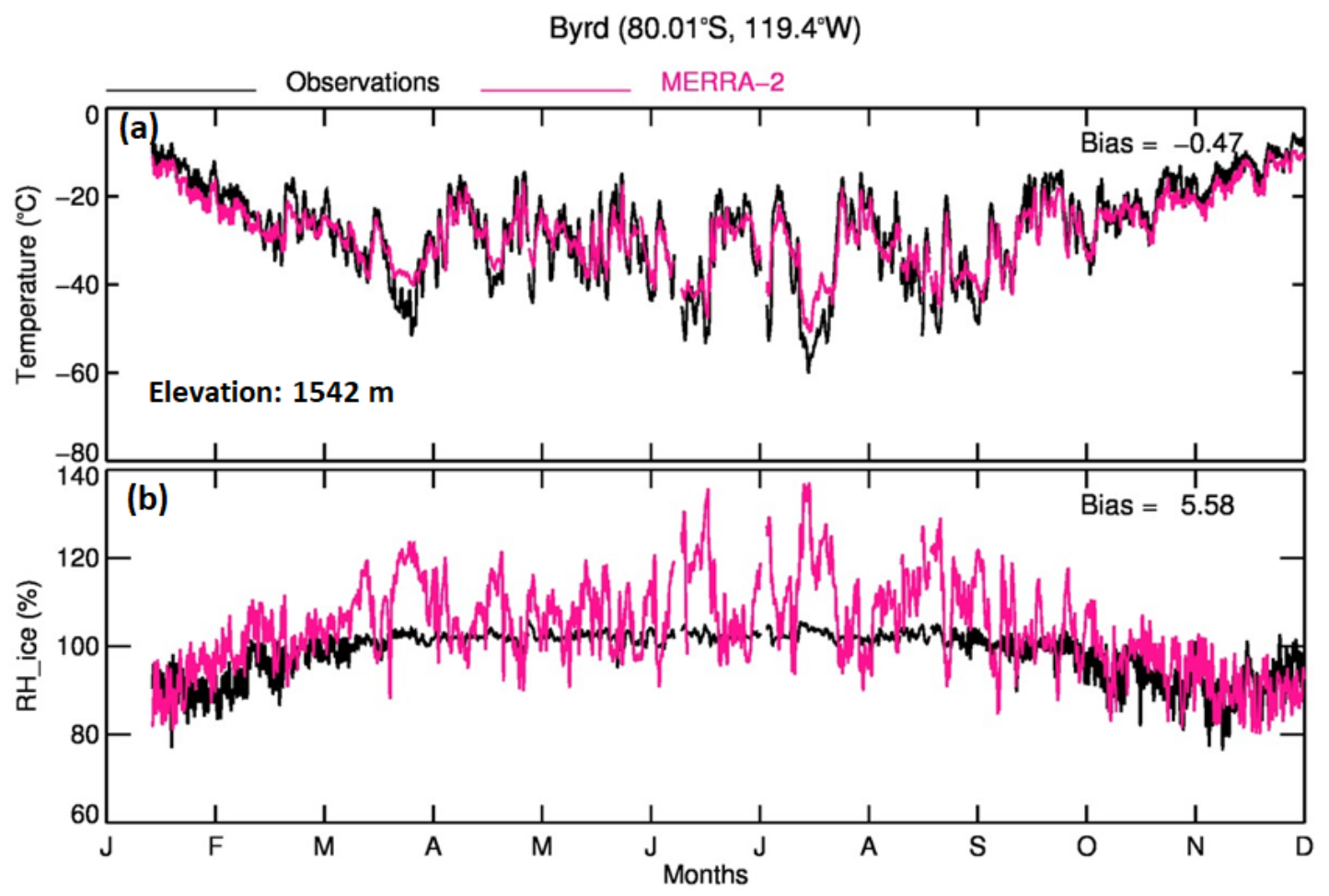

Figure S3. Same as Figure S1, except for AWS Byrd. 


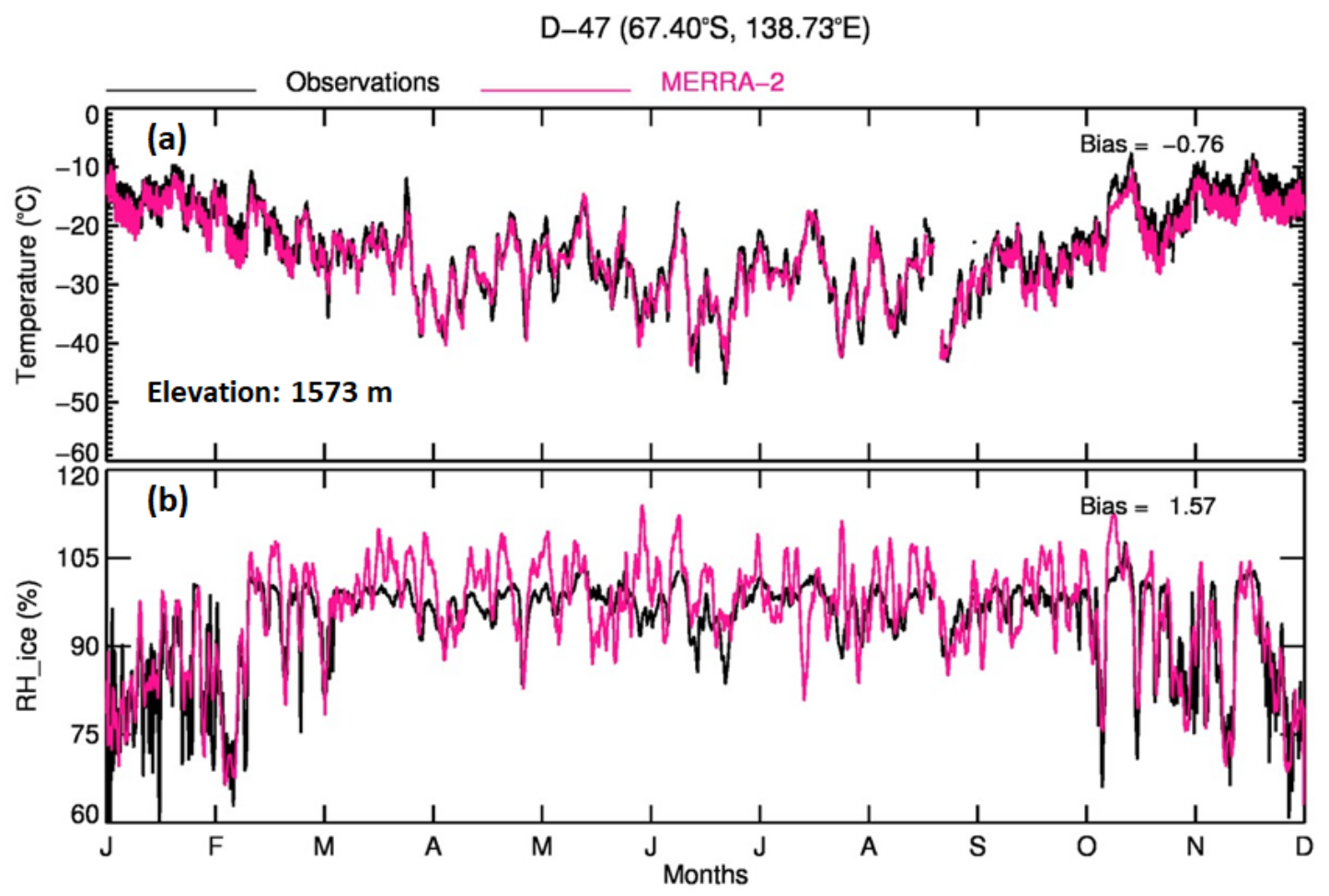

Figure S4. Same as Figure S1, except for AWS D-47. 
Butler Island $\left(72.21^{\circ} \mathrm{S}, 60.17^{\circ} \mathrm{E}\right)$

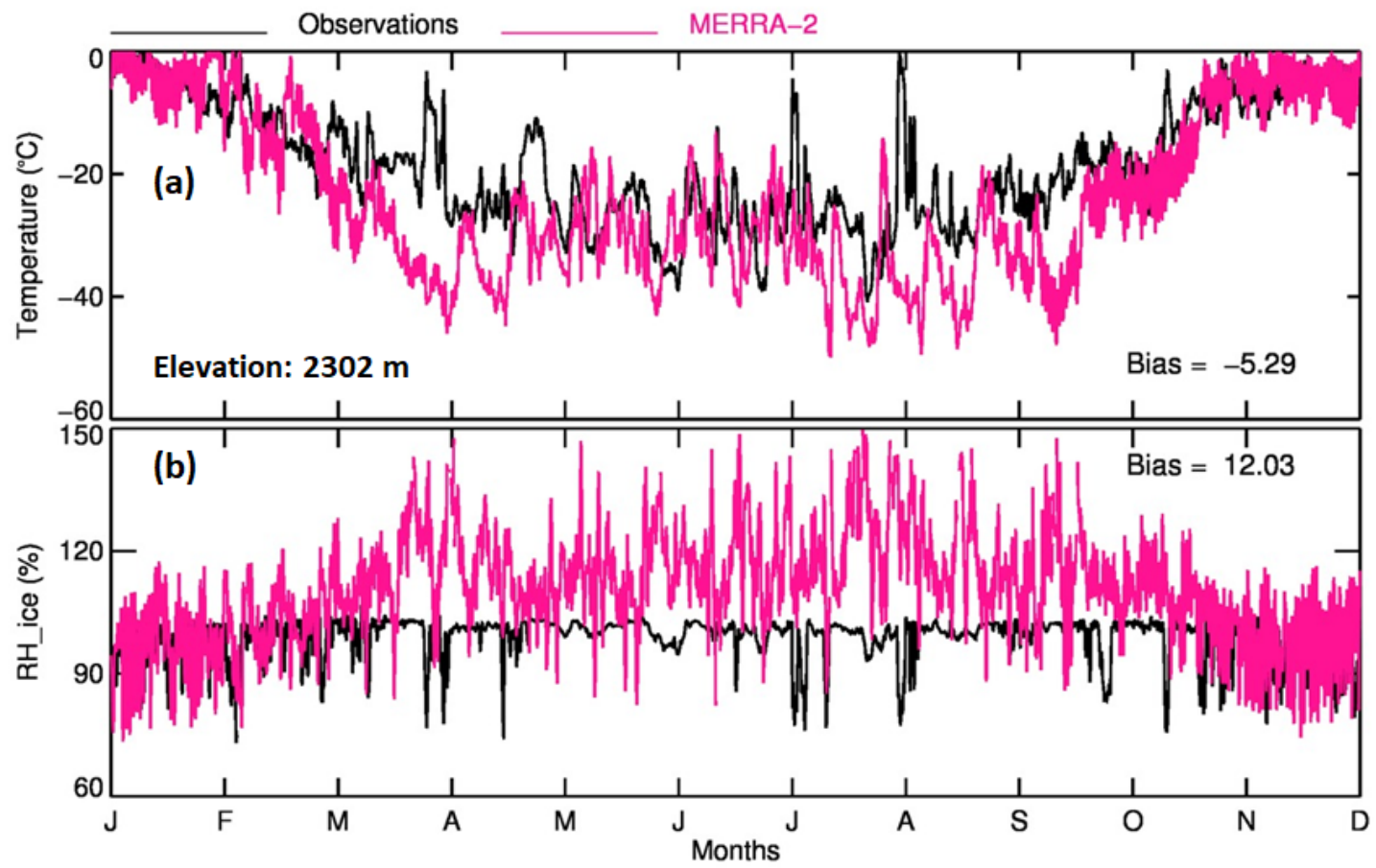

Figure S5. Same as Figure S1, except for AWS Butler Island and for 2009. 


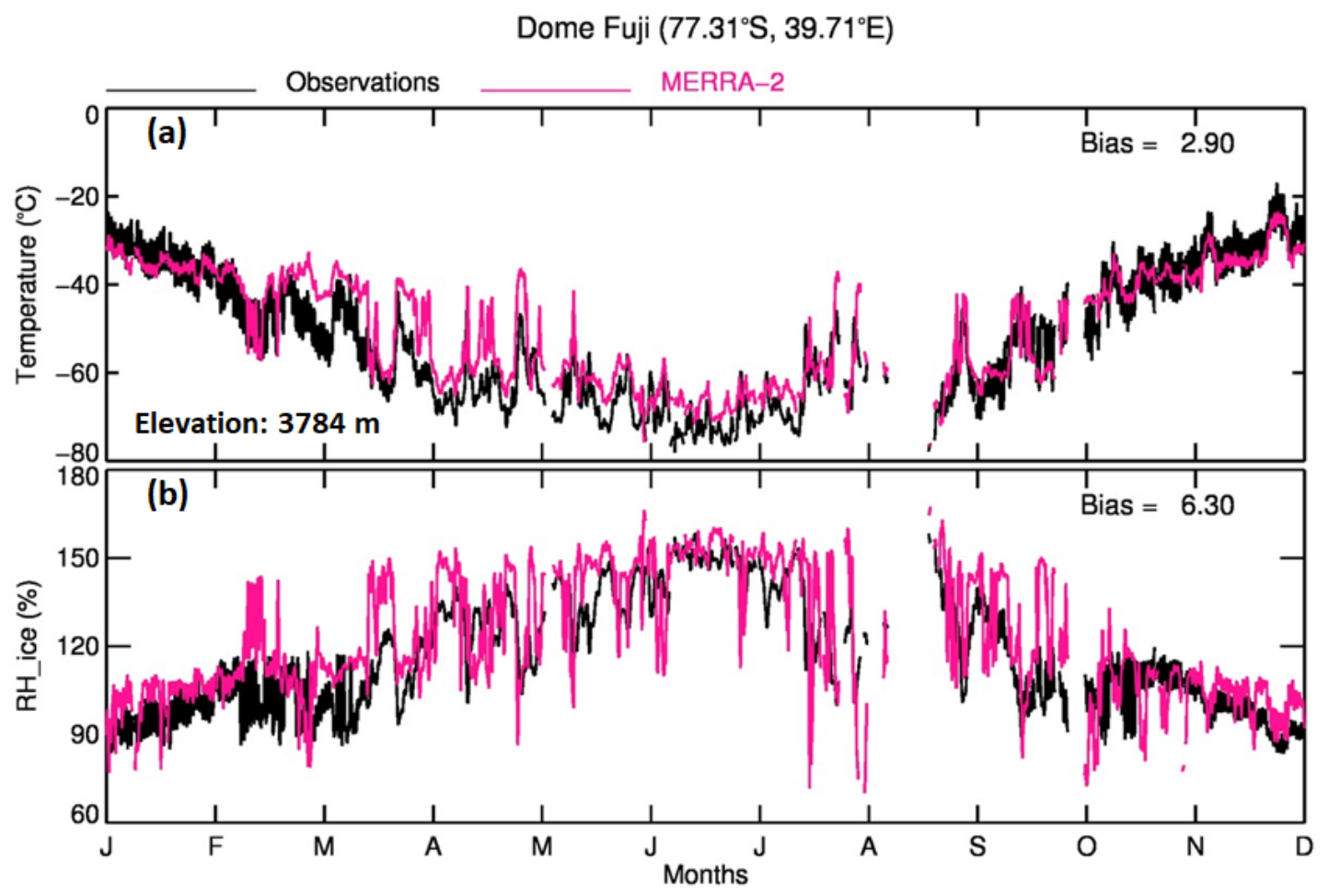

Figure S6. Same as Figure S1, except for AWS Dome Fuji. 

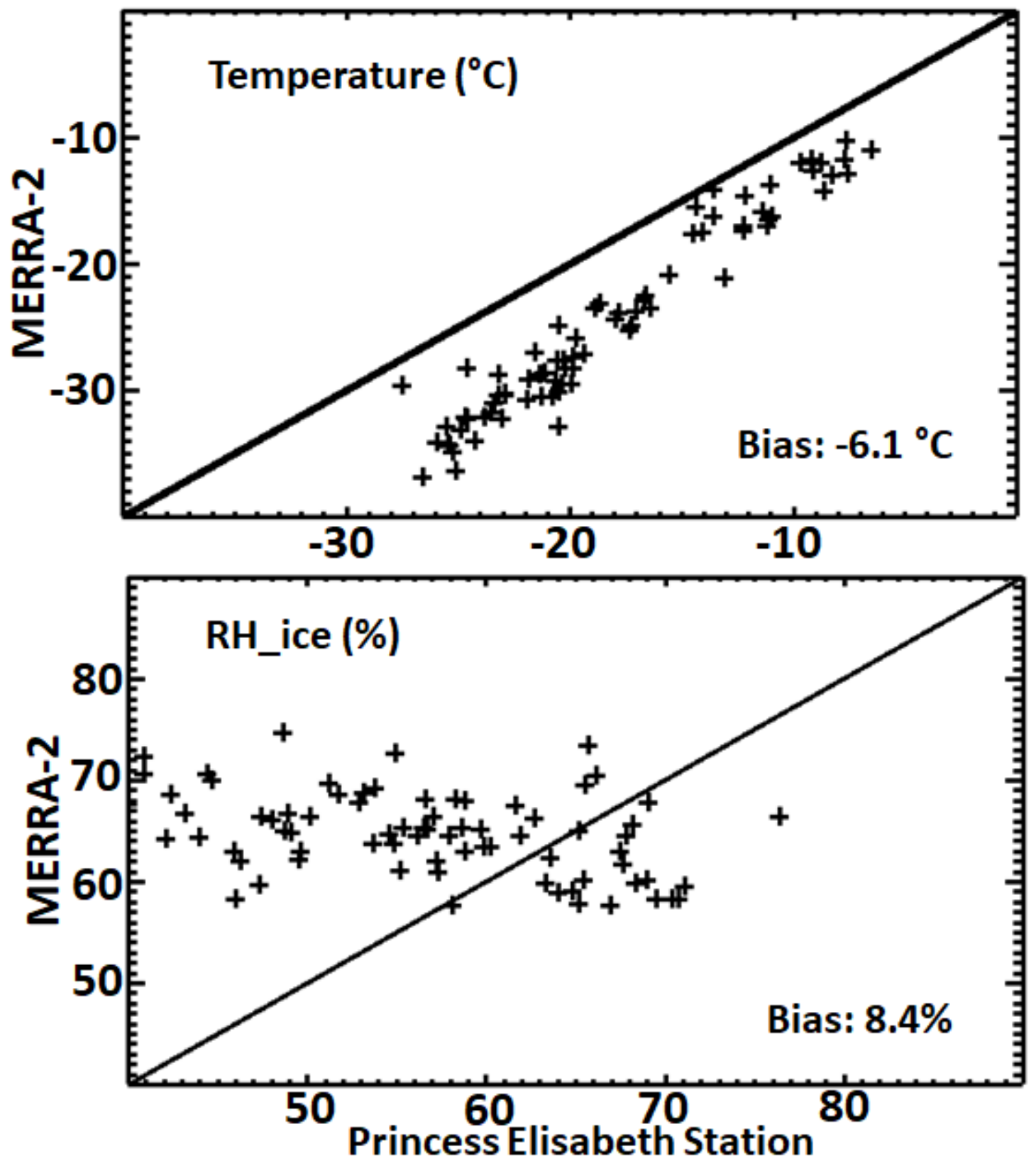

Figure S7. Monthly averaged $2 \mathrm{~m}$ temperature (upper panel) and relative humidity with respect to ice (bottom panel) for the period 2009 - 2015 at Princess Elisabeth Station, Antarctica (x axis) and corresponding MERRA-2 data (y axis). 

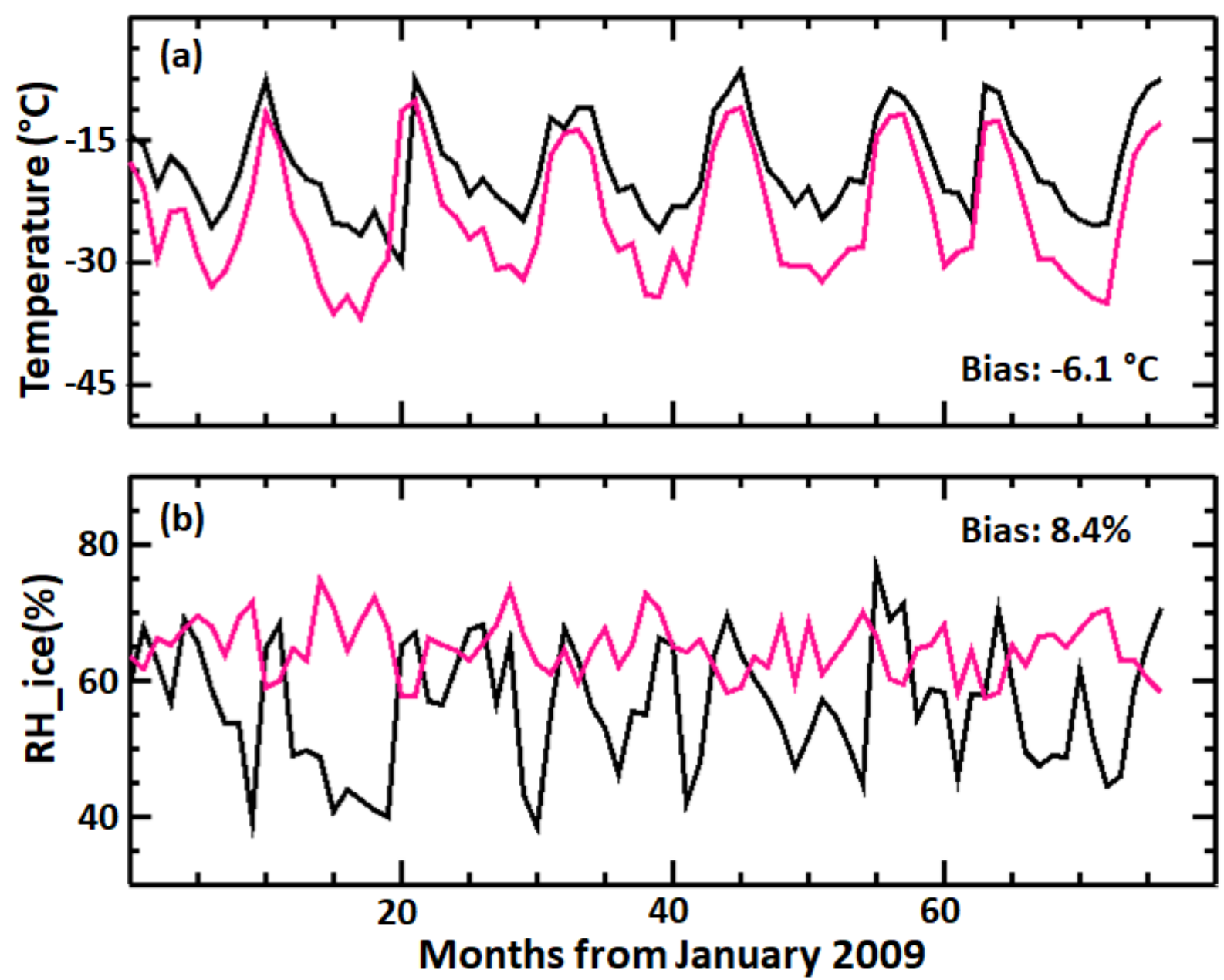

Figure S8. Monthly averaged AWS (black) and MERRA-2 (pink) $2 \mathrm{~m}$ temperature (a) and relative humidity with respect to ice (b) for the period 2009 - 2015 at Princess Elisabeth Station, Antarctica. 
a) MERRA-2

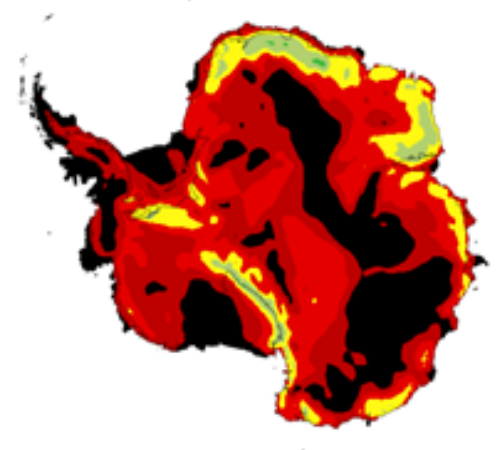

b) ERA-Interim

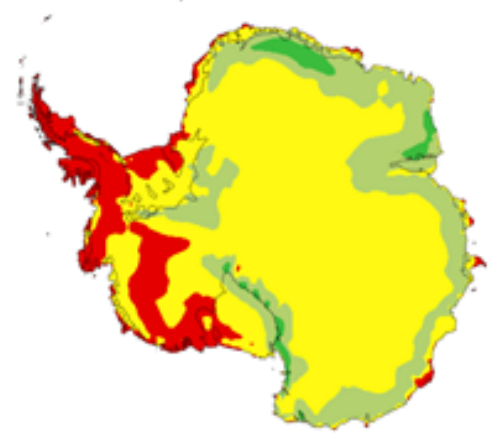

c) AMPS

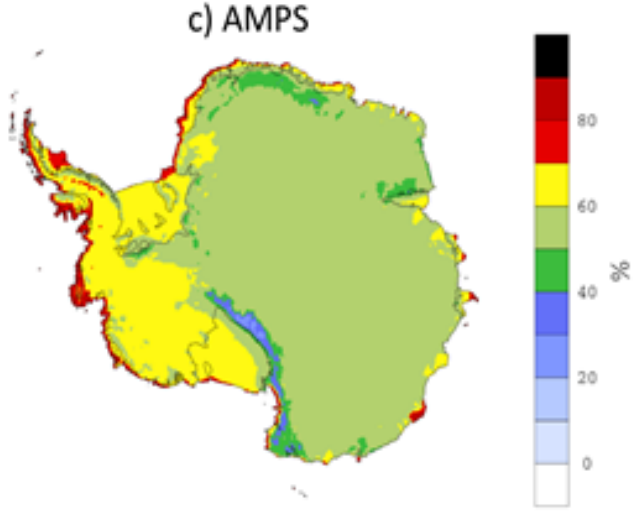

Figure S9. Annual mean relative humidity with respect to water at 2 meters above the surface in 2015 estimated by (c) MERRA-2, (d) ERA-Interim, and (e) AMPS-Polar WRF. 

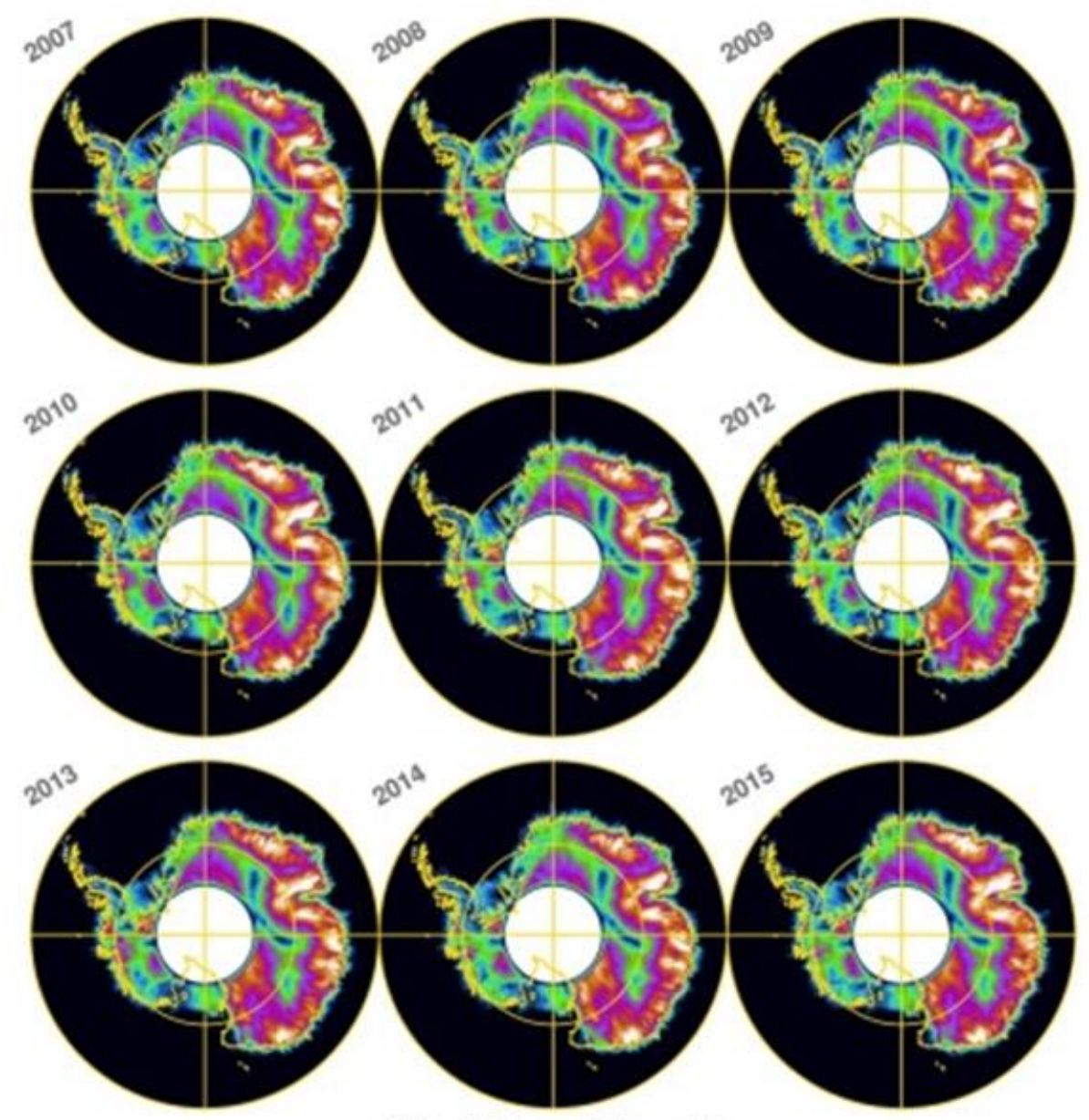

Wind Speed $\left(\mathrm{m} \mathrm{s}^{-1}\right)$

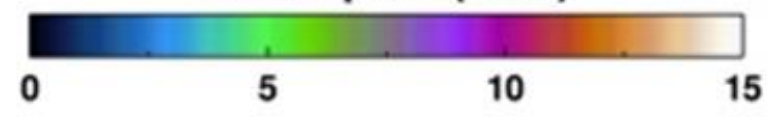

Figure S10. MERRA-2 surface ( $2 \mathrm{~m}$ ) year average wind speed over Antarctica for the period $2007-2015$. 

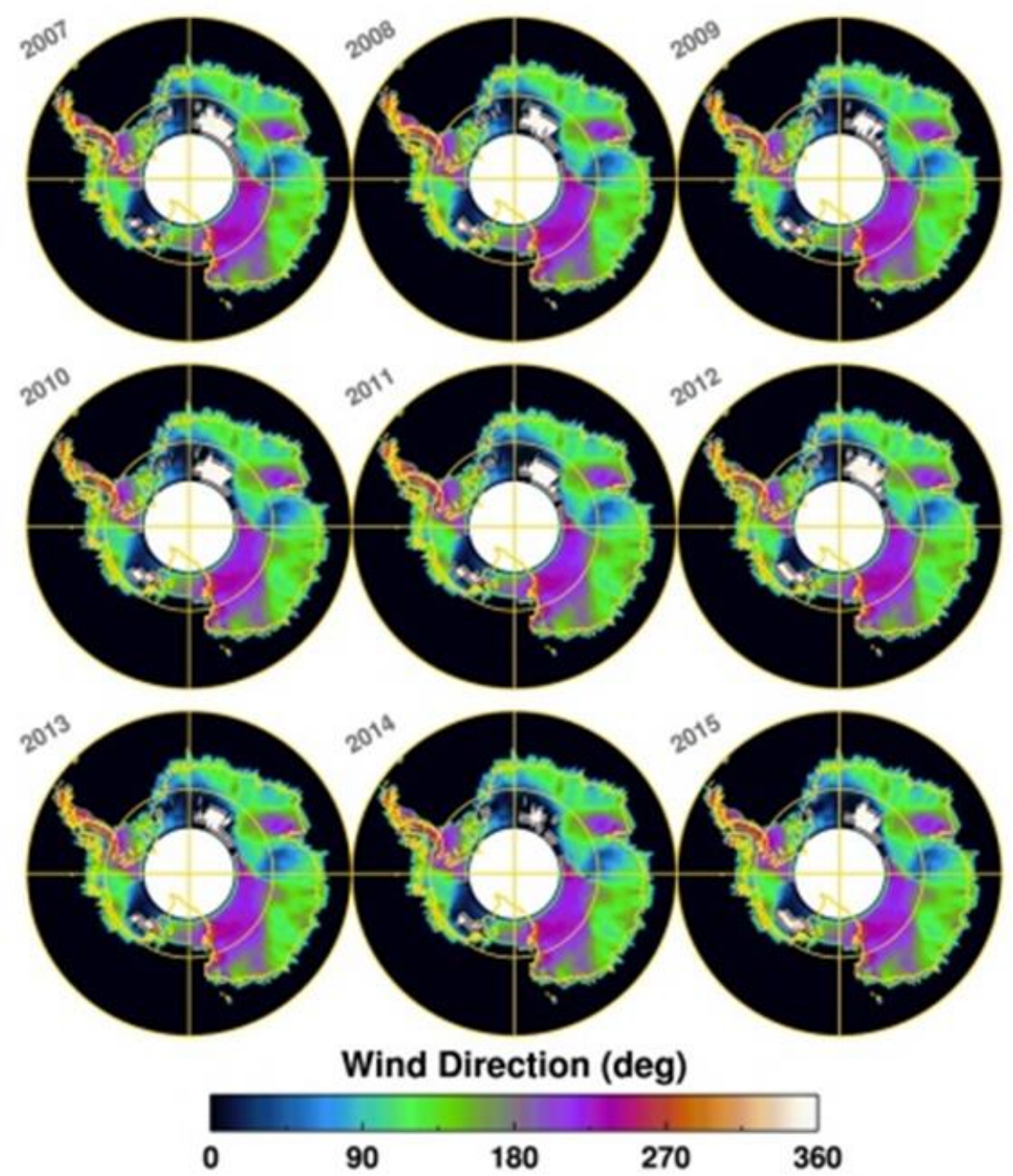

Figure S11. MERRA-2 surface (2 m) year average wind direction over Antarctica for the period 2007 - 2015. 